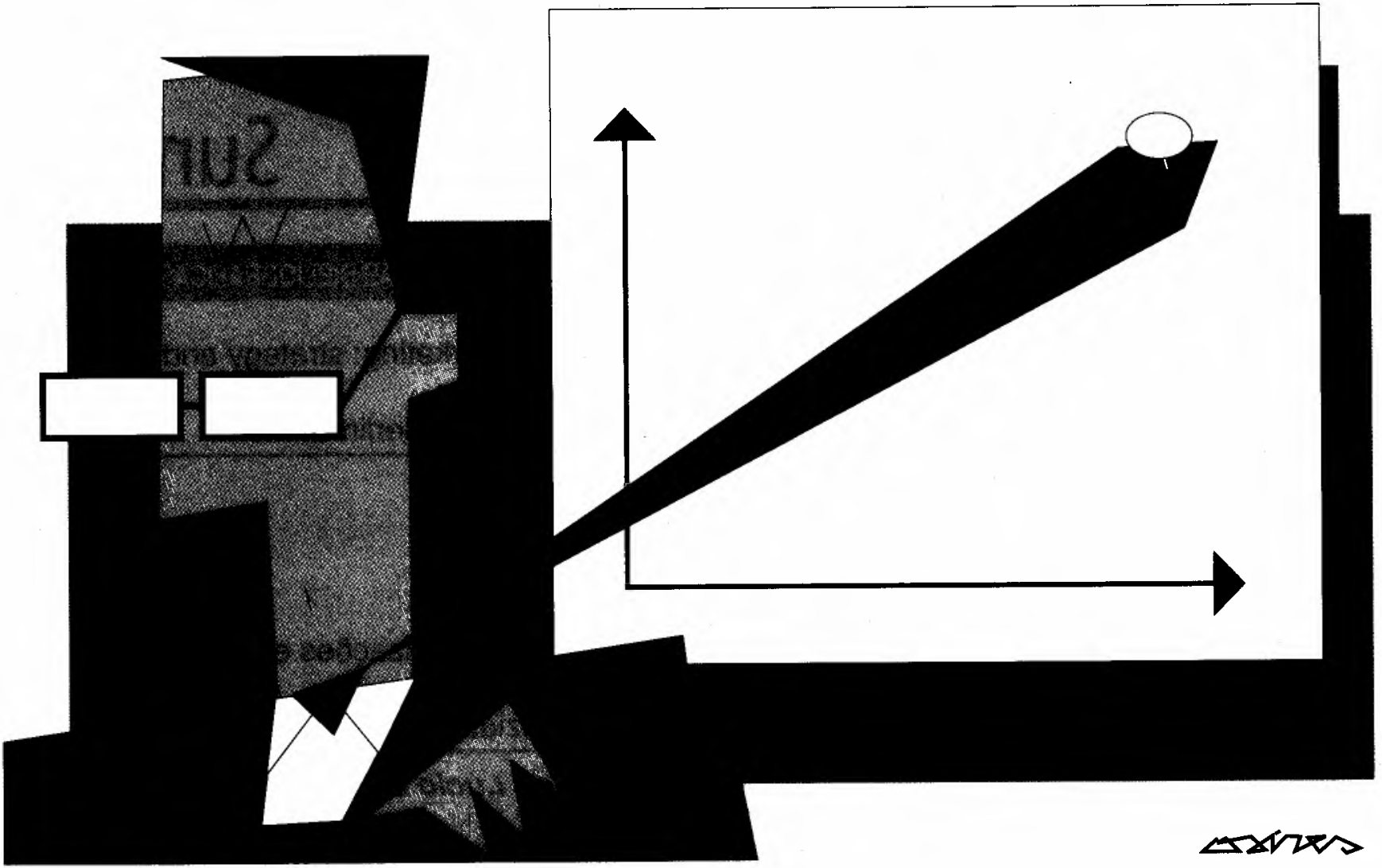

\title{
DESENVOLVIMENTO ECONÔMICO E O EMPRESÁRIO
}

\author{
Ao inovar e executar a reorganização dos fatores de \\ produção, o empresário torna-se $o$ \\ grande propulsor de uma economia em expansão.
}

\section{Luiz Carlos Bresser Pereira}

Professor Titular do Departamento de Planejamento e Análise Econômica Aplicados à Administração da EAESP/FGV.

* RESUMO: O desenvolvimento define-se pelo aumento da produtividade e a reorganização racional da produção, que passa a ocorrer sistematicamente com o advento da industrialização e do capitalismo. Esta reorganização é responsabilidade do empresário, privado ou público, que, nos termos da análise pioneira de Schumpeter, inova comandando o processo de investimento e de introdução do progresso tecnológico. A poupança é realizada principalmente pelo capitalista; o investimento e a inovação, pelo empresário; a direção da empresa, pelo administrador. A função econômica fundamental do Estado é a de criar novas oportunidades para a inovação empresarial.
* PALAVRAS-CHAVE: Desenvolvimento, empresário, estado, administrador, capitalista.

* ABSTRACT: Economic development is identified with productivity increase and the rational reorganization of production, that takes place systematically with the advent of industrialization and capitalism. This reorganization is responsibility of the entrepreneur, who, according to Schumpeter's pioneering analysis, innovates, commanding the investment process and the introduction of technological progress. Savings are primarily achieved by the capitalist; investment and innovation, by the entrepreneur; the direction of the business enterprise, by the manager. The fundamental economic function of the state is to create new opportunities to entrepreneurial innovation.

* KEY WORDS: Development, entrepreneur, state, manager, capitalist. 


\section{INTRODUÇÃO}

Nos últimos anos, o desenvolvimento econômico tornou-se o tema dominante das discussões e dos estudos econômicos. Mas o que se entende por desenvolvimento? Distingue-se de simples crescimento? E qual é o papel do empresário nesse desenvolvimento? É o mesmo do capitalista ou do administrador? E qual a função do Estado? Sua ação completa ou substitui a do empresário? Estas são algumas das perguntas que tentaremos responder neste artigo, procurando conceituar o desenvolvimento econômico e determinar quais são os elementos estratégicos na sua consecução.

\section{O CONCEITO DE DESENVOLVIMENTO}

Desenvolvimento econômico é geralmente definido como o aumento da produção per capita através da reorganização dos fatores de produção. Esta definição não distingue desenvolvimento de crescimento. Em certos casos, todavia, é de toda conveniência que tal distinção seja feita. Tanto desenvolvimento quanto crescimento envolveriam aumento da produtividade, da produção de bens e serviços por homem-hora. Desenvolvimento, porém, implicaria em uma modificação de toda a estrutura econômica e social da região em foco, ao passo que para haver crescimento econômico bastaria que a renda per capita aumentasse. É certo que em muitos casos tal distinção é perigosa, só levando a confusões. A aceitar-se a mesma em sua íntegra, ficaríamos, por exemplo, impossibilitados de comparar em termos objetivos o desenvolvimento econômico de dois países, ou até de um mesmo país em períodos diferentes. Por outro lado, a constatação de que o desenvolvimento econômico é um processo que se realiza por fases mais ou menos definidas é hoje cada vez mais geral. A passagem da fase pré-industrial para a industrial, por exemplo, representa um momento crucial na história de um país, momento esse que os números frios do produto nacional freqüentemente não traduzirão. Enquanto a fase de arranco, conforme a definiu W.W. Rostow ${ }^{1}$, enquanto a revolução industrial de um país não se verifica, a taxa de crescimento de sua renda nacional é muitas vezes enganadora.
Um país cuja economia se baseia na exportação de matérias-primas ou de produtos alimentícios pode, por exemplo, apresentar um rápido crescimento de sua renda devido a uma súbita melhoria nas relações de troca, causada pela elevação do preço de seus produtos de exportação, ou mesmo um aumento da produção dos bens exportáveis causado pelo aumento da procura internacional ou pela abertura de novos mercados. Tal fato indica crescimento econômico, mas, na medida em que a renda extra obtida seja empolgada e consumida por uma minoria inteiramente desinteressada em realizar investimentos produtos e diversificar a produção, não deveremos, a rigor, falar em desenvolvimento.

$$
\begin{gathered}
\text { Schumpeter, cuja contribuição para } \\
\text { a teoria do desenvolvimento } \\
\text { econômico, com a teoria do } \\
\text { empresário, constitui um dos } \\
\text { pontos altos da história da ciência } \\
\text { econômica, define o empresário } \\
\text { como o inovador, o indivíduo } \\
\text { que põe em execução } \\
\text { novas combinaçôes. }
\end{gathered}
$$

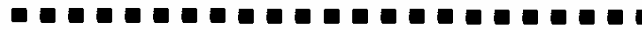

A substituição de estruturas sócio-econômicas tradicionais, de base patriarcal ou feudal, por estruturas mais racionais, de caráter capitalista ou socialista, deve ser considerada como condição de processo de desenvolvimento econômico. Quando tal substituição se realiza, surge um grupo de homens dentro da sociedade que passa a investir de forma racional e sistemática. A reorganização dos fatores de produção ganha, nesse momento, dinamismo interno, na medida em que o aumento da produtividade e a redução dos custos se torna uma condição de sobrevivência para cada empresa e para o próprio sistema social como um todo. E esse processo de transição, que, na maioria das vezes, corresponde à passagem da fase agrária para a industrial, não se traduz necessariamente no crescimento da renda per capita.

A reorganização sistemática e racional dos fatores de produtos é, portanto, o elemento essencial do desenvolvimento eco-
1. ROSTOW, W.W. Elapas do De senvolvimento Econômico, um Manifesto Näo-Comunista. Rio de Janeiro, Zahar Editores, 1961. 
nômico. Esta reorganização se realiza através de duas formas que se completam: através da reorganização dos fatores já integrados no processo de produção, visando maior eficiência; ou da modificação na proporção dos fatores empregados, aumentando-se a participação do capital em relação ao trabalho. Essas duas formas, que geralmente aparecem conjugadas, estão diretamente relacionadas com as duas causas principais do desenvolvimento econômico - $a$ inovação e a acumulação de capital - causas estas intimamente ligadas à figura do empresário que, como veremos, é um dos elementos estratégicos no processo de desenvolvimento de um país.

\section{O EMPRESÁRIO E A INOVAÇÃO}

A reorganização dos fatores de produção realiza-se no plano nacional e no nível das empresas. Em ambos os níveis, são tomadas decisões que influenciam essa reorganização. $O$ desenvolvimento econômico, portanto, não é função exclusiva das decisões tomadas pelos empresários. Mas, sem dúvida, "a feição característica do desenvolvimento é o crescimento das empresas, isto é, o aparecimento de um pequeno número de pessoas, investidores particulares ou funcionários públicos, que utilizam grandes somas de capital e dão emprego a um grande número de pessoas". ${ }^{2}$ Esse "pequeno número de pessoas" são os empresários, cujo papel dentro do desenvolvimento econômico de um país é crucial.

Em termos amplos, empresário é o dirigente e executor da reorganização dos fatores de produção no nível das empresas. Ele é o agente privado ou público que, em nome próprio, dos acionistas ou do Estado, cria e desenvolve, de forma sistemática $e$ racional (ou seja, na qual são sempre procurados os meios mais adequados para se atingir os fins visados), uma organização econômica bem sucedida. Observe-se que esta racionalidade que atribuímos ao empresário tem origens históricas sobre as quais não nos estenderemos. Deriva do ambiente racionalista que a burguesia mercantil e industrial - classe de onde se originaram os primeiros empresários modernos - desenvolveu a partir da Renascença, opondo-se aos sistemas eminente- mente "irracionais" dos regimes patriarcal e feudal, em que considerações de ordem familiar, religiosa e militar interferiam de forma decisiva na organização econômica. ${ }^{3}$

Schumpeter, cuja contribuição para a teoria do desenvolvimento econômico, com a teoria do empresário, constitui um dos pontos altos da história da ciência econômica, define o empresário como o inovador, o indivíduo que põe em execução novas combinações. ${ }^{4}$ Por outro lado, ele definiu desenvolvimento econômico como a execução de novas combinações de fatores produtivos. ${ }^{5}$ Dessa forma de um golpe só, foi Schumpeter capaz de caracterizar a importância do progresso tecnológico lato sensu e do papel do empresário no desenvolvimento econômico. Desenvolver é inovar, é recompor os fatores de produção, é pôr em execução o progresso tecnológico, e quem inova é exatamente o empresário.

Não pretendemos aqui fazer a análise e a crítica geral da teoria de Schumpeter. Seria provavelmente correto afirmar que exagerou a importância do empresário e da inovação no desenvolvimento, esquecendo ou não dando saliência bastante a outras causas desse processo. Cumpre, todavia, sublinhar que sua capacidade de elaborar, ainda em 1911 - quando o problema do desenvolvimento era relegado a um plano muito secundário dentro da teoria econômica - uma teoria de desenvolvimento que ainda conserva grande atualidade foi verdadeiramente genial. Adam Smith já havia feito uma referência indireta à inovação, ou, em outras palavras, à reorganização dos fatores de produção, quando considerou como causa por excelência do desenvolvimento econômico a divisão do trabalho. Mas foi Schumpeter que levou a idéia da inovação econômica às suas últimas conseqüências. Seu conceito de inovação é amplo. Tão amplo que mereceu de muitos a crítica de ser vago. Dificilmente, porém, ele poderia ter sido mais preciso do que foi.

\section{EMPRESÁRIO, ADMINISTRADOR E CAPITALISTA}

Para Schumpter, existem cinco tipos de inovação:

1) introdução de novos métodos de produção;

2) introdução de novos produtos; 
3) abertura de novos mercados;

4) conquista de nova fonte de matériasprimas e produtos semimanufaturados

5) introdução de nova organização de um setor industrial, através, por exemplo, da criação de uma situação de monopólio ou da quebra de uma posição monopolista. $^{6}$

A amplitude desse conceito, que inclui entre os tipos de inovação a própria criação de uma situação monopolista, deu causa a que sua teoria fosse por alguns considerada mais uma teoria justificativa do lucro do empresário do que do desenvolvimento econômico. Entretanto, se seu conceito de inovação é amplo, isto não impediu Schumpeter de limitar o conceito de empresário, restringindo-o àqueles homens de negócio que inovam de forma absolutamente original. Diz ele: "Alguém é um empresário na medida em que executa novas combinações e deixa de sê-lo assim que, depois de criar seu negócio, instala-se para administrálo da mesma forma que outras pessoas administram seus negócios." 7 Assim, o administrador de empresas é ou não é empresário na medida em que está, naquele momento, inovando.

Essa preocupação em distinguir o empresário do homem de negócios ou do administrador parece-nos legítima. $\mathrm{O}$ administrador rotineiro, que não é capaz de perceber e aproveitar as oportunidades que o desenvolvimento da ciência, a descoberta de novos recursos, o aparecimento de novas necessidades estão constantemente ensejando, não pode ser considerado um empresário. Sua contribuição para o desenvolvimento econômico tem a mesma dimensão que a de qualquer pessoa que executa um trabalho produtivo. A mera manutenção do statu quo apenas merece a classificação de atividade empresarial na medida em que as condições do mercado, por exemplo, sejam conducentes ao declínio da empresa, pois só uma ação decididamente criativa, inovadora, permite que o declínio não se verifique. Não basta apenas manter e talvez aperfeiçoar um pouco a ordem já existente no sistema produtivo, é preciso reorganizá-lo e, muitas vezes, essa reorganização precisa ser radical, para que o desenvolvimento econômico se realize.

É portanto, correto distinguir empresário de administrador, de dirigente de em- presa. Parece-nos, porém, que Schumpeter restringiu excessivamente o conceito. Aquele, por exemplo, que imita de forma bem-sucedida pode também ser considerado um empresário, desde que essa imitação represente uma inovação dentro do âmbito de sua empresa. Além disso, a atividade empresarial não se limita a criar novas empresas. Desenvolvê-las é uma função que exige, muitas vezes, uma ação inovadora decidida. Isto é especialmente verdade nas sociedades industriais modernas, onde existe alguma forma de competição entre as empresas, onde está sempre se verificando uma pressão sobre as empresas para produzirem mais eficientemente.

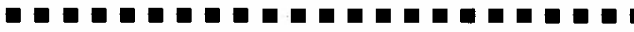 \\ Inovação e acumulação de capital não são duas bases concorrentes para a explicação do desenvolvimento econômico, mas simplesmente dois aspectos de um mesmo processo.}

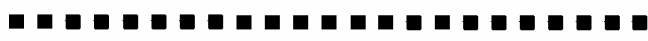

Inovar, encontrar continuamente novas e melhores combinações para os fatores de produção, é, portanto, a característica essencial do empresário. Note-se, porém, que não cabe ao empresário fazer descobertas, invenções. Isto cabe ao cientista, ao técnico, ao inventor, ao explorador de novos recursos. Ao empresário cabe distinguir no que está ocorrendo à sua volta a oportunidade econômica e, em seguida, aproveitar essa oportunidade efetivamente. Dessa forma, ele estará inovando, sendo esta a característica básica e exclusiva de sua contribuição ao desenvolvimento econômico de um país.

Procurou-se - e ainda hoje esta tese tem defensores - definir o empresário como aquele que se dispõe a correr riscos. Entre as muitas restrições que tal definição merece, a mais grave é a de que leva a confundir a pessoa do capitalista com a do empresário. Quando se fala em risco, estáse pensando em risco econômico de perder o que foi investido. Ora, quem corre esse risco é o capitalista, não o empresário. É
6. Idem, ibidem.

7. Idem, ibidem; p.78. 
certo que, nas primeiras fases do capitalismo, a pessoa do capitalista e do empresário tendem a confundir-se. O empresário é geralmente um capitalista, embora, mesmo nessa ocasião, freqüentemente não use apenas recursos próprios para investir. Nas fases mais adiantadas do capitalismo, porém, o empresário tende a tornar-se um empregado, um agente dos acionistas. Nesse momento, o único risco que corre é o de perder sua posição dentro da empresa. O risco de perder o que foi investido é dos acionistas e financiadores da empresa.

\section{ACUMULAÇÃO DE CAPITAL}

O desenvolvimento econômico se realiza através de uma organização mais eficiente dos fatores produtivos existentes, ou do aumento da proporção do capital para o trabalho. No primeiro caso, temos a inovação em sua forma mais pura, no segundo, que é, via de regra, mais importante, inovação implica em inversão, em acumulação de capital. Inovação e acumulação de capital não são duas bases concorrentes para a explicação do desenvolvimento econômico, mas simplesmente dois aspectos de um mesmo processo. Porque o papel do empresário não é tão crucial (embora, como veremos, de grande importância) no processo de acumulação de capital, os defensores da teoria do empresário tendem a não lhe atribuir a devida atenção. Na verdade, a inovaçāo sem a acumulação de capital é, na grande maioria dos casos, impossível. Por outro lado, a acumulação de capital sem a inovação levará, mais cedo ou mais tarde, a um estancamento das oportunidades de investimento e, conseqüentemente, da própria acumulação de capital.

Já nos referimos ao papel do empresário na inovação. E o seu papel na acumulação de capital? A acumulação de capital é primordialmente função da taxa de poupança. Cabe, portanto, perguntar qual é o papel do empresário na determinação da poupança nacional. Muito sumariamente, esse papel é duplo. Se, nas primeiras etapas do desenvolvimento econômico de um país - aceitando-se a classificação de W.Arthur Lewis - dividirmos uma sociedade em cinco classes sócio-econômicas capitalista, dos senhores de terra, média, to que a única classe com capacidade para poupar e inverter de forma substancial e sistemática é a capitalista.

Na medida em que, nessa época, empresários e capitalistas tendem a confundir-se em uma só pessoa, a importância do empresário na formação de poupança é evidente. Nos países capitalistas avançados e nos países socialistas, a função do empresário como agente de poupança é também de grande significado, pois cabe a ele decidir a respeito da retenção dos lucros nas empresas para reinvestimento. Os lucros não distribuídos são hoje uma das maiores fontes de poupanças nos países desenvolvidos. ${ }^{8}$ Ao retê-los, o empresário poupa o que não é seu. Colocado em uma posição estratégica, ele promove um tipo de poupança forçada.

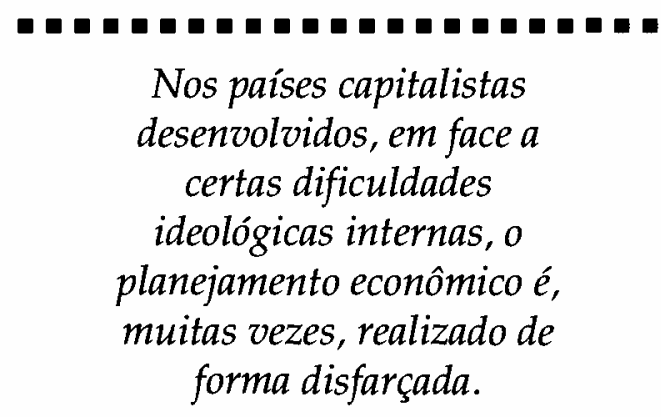

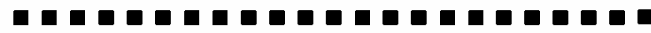

O lucro não distribuído, todavia, só tem sentido na medida em que se destina ao investimento, à acumulação de capital. Ora, as decisões de investimento cabem precipuamente ao empresário. Empresário é quase sinônimo de investidor. (É claro que estamos referindo-nos aos investimentos em bens de capital dentro da empresa e não à inversão que faz o capitalista quando compra ações de uma companhia no mercado de títulos.) E ainda é preciso levar em consideração, a fim de sublinhar o papel do empresário na formação de poupança, que esta tanto determina o investimento quanto é por ele determinada. Se, momentaneamente, a taxa de poupança excede a de investimento, a primeira (e a própria renda nacional) só não se reduzirá para igualar o investimento se tal desequilíbrio não for imediatamente corrigido.

É nesse momento, quando a ameaça de crise econômica paira sobre o país, que o papel do empresário torna-se particular- 
mente decisivo. É famoso o caso do presidente de uma grande companhia americana que, em meio a uma depressão, decidiu fazer um investimento de um bilhão de dólares. Dentro desse mesmo esquema, John E.Sawyer, examinando as causas do extraordinário desenvolvimento econômico dos Estados Unidos no século passado, afirma que uma delas foi o exagerado otimismo revelado pelos empresários americanos, otimismo esse que levou ao aumento da taxa de acumulação de capital do país. "Os empresários", diz ele, "faziam previsões exageradas das possibilidades de crescimento, mas essas previsões exageradas individuais e coletivas operaram no sentido de acelerar o processo de crescimento e, freqüentemente, em várias medidas, produziram resultados que, ex post, tornaram econômicas as previsões exageradas iniciais".

\section{O EMPRESÁRIO E O ESTADO}

Vimos até aqui que a reorganização dos fatores de produção no nível das empresas, através da inovação e da acumulação de capital, define, ao mesmo tempo, o processo de desenvolvimento econômico e a função do empresário. Ora, o empresário inova e investe na medida em que percebe oportunidades para tal. O gênio do empresário está em saber ver a oportunidade e em aproveitá-la. Entretanto, a oportunidade econômica é um fenômeno exterior ao empresário. Ele se torna um agente criador de oportunidades para outros apenas na medida em que investe. De um modo geral, porém, não obstante sua grande importância para o desenvolvimento econômico de um país, a existência de oportunidades econômicas está fora do controle dos empresários.

Este fato é importante por dois motivos: porque impõe um limite à contribuição do empresário para o desenvolvimento econômico; e porque nos sugere qual seja o papel do Estado nesse mesmo desenvolvimento nos países capitalistas.

Para que oportunidades econômicas existam, certas condições institucionais são necessárias. Entre elas, a manutenção da ordem, de forma a assegurar ao empresário os frutos do seu esforço, é uma das mais importantes, de tal forma que, na época do Estado liberal, era esta a função por exce- lência do estado. Desde que essa e outras condições institucionais - entre as quais vale ainda a pena citar o prestígio que a atividade empresarial envolve e as possibilidades de mobilidade social no sentido vertical que a sociedade apresenta para o empresário em termos gerais a investir, as oportunidades específicas de investimentos poderão ter duas origens.

Poderão surgir mais ou menos ao acaso, como resultado do progresso tecnológico não planejado, de novas descobertas de recursos, de modificações no mercado etc.; ou poderão ser proporcionadas pelo Estado, através de um sistema de incentivos e punições para o investimento. Neste último caso, estaremos diante de um sistema de planejamento econômico, que tem por objetivo precípuo a promoção de oportunidades econômicas de investimento. Criar oportunidades novas para a atividade empresarial torna-se, então, a função econômica essencial do Estado.

É isto, aliás, o que vem ocorrendo na maioria dos países da atualidade. Nos países capitalistas desenvolvidos, em face a certas dificuldades ideológicas internas, o planejamento econômico é, muitas vezes, realizado de forma disfarçada. Mas nos países subdesenvolvidos, quando estes não tomam iniciativa por conta própria, são os próprios países desenvolvidos que os estimulam a planejar suas economias.

$$
\begin{gathered}
\text { Um país que permite que as } \\
\text { oportunidades econômicas } \\
\text { surjam ao acaso, sem nenhum } \\
\text { controle, quando tantos } \\
\text { controles nos são hoje oferecidos } \\
\text { pelas ciências sociais e } \\
\text { particularmente pela economia, } \\
\text { está deixando de usar um } \\
\text { instrumento precioso na } \\
\text { promoção de seu } \\
\text { desenvolvimento. }
\end{gathered}
$$

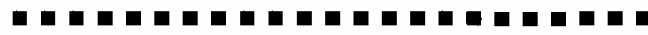

Paradoxalmente, é isto o que aconteceu no sudeste da Ásia, com o "Plano Colombo", e na América Latina, com a "Aliança para o Progresso". E mesmo nos países socialistas, isto se vem verificando até cer-
9. SAWYER, John E. Entrepreneurship in Periods of Rapid Growth: The United States in the 19th Century. Material Mimeografado, 1954, p.4. 
to ponto. Nesses países não é possível separar claramente o Estado das empresas, mas é perfeitamente viável distinguir o Governo das empresas. Assim, na Iugoslávia - considerada pelos soviéticos um país socialista de direita -, o governo planeja a economia, estabelece um sistema de incentivos e punições, criando, dessa forma, oportunidades econômicas. Ali, as decisões de investimento são claramente descentralizadas, ficando em grande parte a critério das empresas existentes e das municipalidades. Dentro das empresas e das municipalidades caberá às pessoas com espírito empresarial aproveitar essas oportunidades.

\section{CONCLUSÕES}

Os empresários e o Estado são, portanto, os dois agentes estratégicos do desenvolvimento. $\mathrm{O}$ Estado cria as oportunidades, estabelece as condições e os estímulos próprios ao investimento, de acordo com um plano geral de reorganização do sistema produtivo. Os empresários aproveitam as oportunidades, reorganizando os fatores de produção no nível da empresa.

Discutir qual dos dois agentes é o mais importante no processo de desenvolvimento é ocioso. Um país que permite que as oportunidades econômicas surjam ao acaso, sem nenhum controle, quando tantos controles nos são hoje oferecidos pelas ciências sociais e particularmente pela economia, está deixando de usar um instrumento precioso na promoção de seu desenvolvimento. Só se desenvolverá se, além de ser dotado de uma riqueza de recursos extraordinária, for auxiliado por uma série de circunstâncias internas e externas favoráveis.

Este foi o caso dos Estados Unidos e da Europa Ocidental. Por outro lado, centralizar todas as decisões nas mãos de um pequeno grupo de líderes políticos e técnicos governamentais, além de outras desvantagens, apresenta dificuldades econômicas sérias, que a própria União Soviética vem, ao que parece, reconhecendo. Assim, nos países socialistas, a tendência parece ser para a formação de um grupo empresarial com uma autonomia de decisão muito maior do que aquela que os modelos teóricos socialistas faziam prever.

Vemos, portanto, que, embora esse problema se coloque em geral em termos ideológicos, tornando impossível qualquer discussão mais serena, a prática e o bom senso nos levam a concluir que os empresários e o Estado, e não apenas aqueles ou este, são, hoje, os dois agentes por excelência do desenvolvimento econômico.

\section{BIBLIOGRAFIA SUPLEMENTAR}

COLE, Arthur H. Business Enterprise in its Social Setting. Cambridge, Mass., Harvard University Press, 1959.

HIGGINS, Benjamin. Economic Development. New York, W.W. Norton \& Company, 1959.

HOSELITZ, Bert F. " The Early History of Entrepreneurial Theory". Explorations in Entrepreneurial History, $\mathrm{n}^{\mathrm{Q}}$ 3, 1950-51, pp.193-220.
HOSELITZ, Bert F. Sociological Aspects of Economic Growth, Illinois, The Free Press of Glencoe, 1961.

REDLICH, Fritz L. "The Origin of the Concepts of 'Entrepreneur' and 'Creative Entrepreneurship"'. Explorations in Entrepreneurial History, $\mathrm{n}^{\mathrm{o}}$ 1, 1949, pp. 1-7.

SCHUMPETER, Joseph A. Business Cycles. New York, McGraw-Hill, 1939. . 